University of Wollongong

Research Online

Faculty of Engineering and Information

Faculty of Engineering and Information

Sciences - Papers: Part A

Sciences

$1-1-2012$

Synthesis of W03@Graphene composite for enhanced photocatalytic oxygen evolution from water

Jingjing Guo

Shanghai Jiao Tong University

Yao Li

State Key Laboratory of Metal Matrix Composites

Shenmin Zhu

Shanghai Jiao Tong University

Zhixin Chen

University of Wollongong, zchen@uow.edu.au

Qinglei Liu

Shanghai Jiao Tong University

See next page for additional authors

Follow this and additional works at: https://ro.uow.edu.au/eispapers

Research Online is the open access institutional repository for the University of Wollongong. For further information contact the UOW Library: research-pubs@uow.edu.au 


\title{
Synthesis of W03@Graphene composite for enhanced photocatalytic oxygen evolution from water
}

\begin{abstract}
"Nano tungsten oxide (WO3) particles were synthesized on the surface of graphene (GR) sheets by using a simple sonochemical method. The obtained composite, WO3@GR, was characterized by X-ray diffraction, $\mathrm{N}-2$ adsorption/desorption analysis, thermo-gravimetric analysis, Raman spectroscopy and UV-vis diffuse reflectance spectra measurements. It was found that chemical bonds between the nano WO3 particles and the GR sheets were formed. The average particle size of the WO3 was evidenced to be around $12 \mathrm{~nm}$ on the GR sheets. When used as photocatalyst for water splitting, the amount of evolved 0-2 from water for the W03@GR composite with 40 wt\% GR inside was twice and 1.8 times as much as that for pure WO3 and mixed-WO3/GR, respectively. The excellent photocatalytic property of the W03@GR composite is due to the synergistic effects of the combined nano WO3 particles and GR sheets. The sensitization of WO3 by GR enhances the visible light absorption property of WO3@GR. The chemical bonding between WO3 and GR minimizes the interface defects, reducing the recombination of the photogenerated electron-hole pairs. Furthermore, the GR sheets in the WO3@GR composite enhance electrons transport by providing low resistance conduction pathways, leading to improved photo-conversion efficiency. The methodology opens up a new way of obtaining photoactive GR-semiconductor composites for photodissociating water under visible light."
\end{abstract}

\section{Keywords}

graphene, water, evolution, oxygen, wo3, photocatalytic, synthesis, enhanced, composite

\section{Publication Details}

Guo, J., Li, Y., Zhu, S., Chen, Z., Liu, Q., Zhang, D., Moon, W. \& Song, D. (2012). Synthesis of WO3@Graphene composite for enhanced photocatalytic oxygen evolution from water. RSC Advances, 2 (4), 1356-1363.

\section{Authors}

Jingjing Guo, Yao Li, Shenmin Zhu, Zhixin Chen, Qinglei Liu, Di Zhang, Won-Jin Moon, and Deok-Min Song 


\title{
RSC Advances
}

\section{Synthesis of $\mathrm{WO}_{3} @$ Graphene composite for enhanced photocatalytic oxygen evolution from water}

\author{
Jingjing Guo, ${ }^{a}$ Yao Li, ${ }^{a}$ Shenmin Zhu, ${ }^{a}{ }^{a}$ Zhixin Chen, ${ }^{b}$ Qinglei Liu, ${ }^{a}$ Di Zhang, ${ }^{* a}$ Won-Jin Moon ${ }^{c}$ and Deok- \\ Min Song ${ }^{c}$
}

Received 22nd August 2011, Accepted 26th October 2011

DOI: 10.1039/c1ra00621e

\begin{abstract}
Nano tungsten oxide $\left(\mathrm{WO}_{3}\right)$ particles were synthesized on the surface of graphene (GR) sheets by using a simple sonochemical method. The obtained composite, $\mathrm{WO}_{3} @ \mathrm{GR}$, was characterized by $\mathrm{X}$-ray diffraction, $\mathrm{N}_{2}$ adsorption/desorption analysis, thermo-gravimetric analysis, Raman spectroscopy and UV-vis diffuse reflectance spectra measurements. It was found that chemical bonds between the nano $\mathrm{WO}_{3}$ particles and the GR sheets were formed. The average particle size of the $\mathrm{WO}_{3}$ was evidenced to be around $12 \mathrm{~nm}$ on the GR sheets. When used as photocatalyst for water splitting, the amount of evolved $\mathrm{O}_{2}$ from water for the $\mathrm{WO}_{3} @ \mathrm{GR}$ composite with $40 \mathrm{wt} \% \mathrm{GR}$ inside was twice and 1.8 times as much as that for pure $\mathrm{WO}_{3}$ and mixed- $\mathrm{WO}_{3} / \mathrm{GR}$, respectively. The excellent photocatalytic property of the $\mathrm{WO}_{3} @ \mathrm{GR}$ composite is due to the synergistic effects of the combined nano $\mathrm{WO}_{3}$ particles and GR sheets. The sensitization of $\mathrm{WO}_{3}$ by GR enhances the visible light absorption property of $\mathrm{WO}_{3} @ \mathrm{GR}$. The chemical bonding between $\mathrm{WO}_{3}$ and GR minimizes the interface defects, reducing the recombination of the photo-generated electron-hole pairs.

Furthermore, the GR sheets in the $\mathrm{WO}_{3} @$ GR composite enhance electrons transport by providing low resistance conduction pathways, leading to improved photo-conversion efficiency. The methodology opens up a new way of obtaining photoactive GR-semiconductor composites for photodissociating water under visible light.
\end{abstract}

\section{Introduction}

Recently, great interest has been focused on semiconductor photocatalysis utilizing solar energy to photodissociate water. ${ }^{1-5}$ Solar photolysis of water is one of the cleanest ways of producing hydrogen and oxygen, which has great potential in solving energy problem. As a semiconductor for spontaneous photolysis, three main thermodynamic requirements should be fulfilled: (1) its band gap must be higher than water decomposition voltage $(1.23 \mathrm{eV})$; (2) its band edge positions must straddle the hydrogen and oxygen redox potential, and (3) it must be stable against photo corrosion during photocatalysis. Accordingly, semiconductors including $\mathrm{TiO}_{2}, \mathrm{WO}_{3}, \mathrm{Bi}_{2} \mathrm{WO}_{6}, \mathrm{ZnO}, \mathrm{Bi}_{2} \mathrm{O}_{3}$ and $\mathrm{CdS}$ etc. have been reported to be used in water splitting to produce hydrogen or oxygen. ${ }^{6-12}$ Among them, $\mathrm{TiO}_{2}$ is the most extensively studied photocatalyst for its low toxicity, long-term thermodynamic stability, high photostability, and high efficiency. ${ }^{5,12,13}$ Unfortunately, $\mathrm{TiO}_{2}$ is only active in the ultraviolet

${ }^{a}$ State Key Laboratory of Metal Matrix Composites, Shanghai Jiao Tong University, 800 Dongchuan Road, Shanghai, 200240, P. R. China.

E-mail: smzhu@sjtu.edu.cn, zhangdi@sjtu.edu.cn; Fax: +86-21-34202749; Tel: +86-21-34202584

${ }^{b}$ Faculty of Engineering, University of Wollongong, Wollongong, NSW, 2522, Australia

${ }^{c}$ Gwang ju Center, Korea Basic Science Institute Chonnam National University, 300 YongBong-Dong, Buk-Gu, Gwang ju, 500-757, Korea light range due to its wide band gap $(3.2 \mathrm{eV})$, result in utilizing only $5 \%$ of the total solar spectrum.

Nanostructured tungsten trioxide $\left(\mathrm{WO}_{3}\right)$, as one of the $\mathrm{n}$ type semiconductors with a band gap of $2.8 \mathrm{eV}$, has attracted a lot of interests in photocatalysis because of its strong adsorption within the solar spectrum $(\leqslant 500 \mathrm{~nm})$, stable physicochemical properties as well as its resilience to photo corrosions. ${ }^{71-16}$ Under the irradiation of visible light, photoinduced electrons and holes can be produced in the conduction band and valence band of $\mathrm{WO}_{3}$, respectively. The photo generated holes can be used to drive the water-splitting reaction to produce oxygen. Generally, nanocrystalline semiconductors have poor charge mobility and thus produce very limited photocurrent. ${ }^{5,17,18}$ The poor mobility combined with inherently slow water oxidation reactions often results in the high degree of electron and hole recombination either with the defect and trap states or within grain boundaries, which diminishes the efficiency of the photocatalytic reaction significantly. This is one of the biggest obstacles hindering the development of $\mathrm{WO}_{3}$ as a practical photocatalyst. ${ }^{2,19}$ One possible technique of improving the efficiency of electron-hole pair separation in $\mathrm{WO}_{3}$ is to dope $\mathrm{WO}_{3}$ with other elements or compound (Ag, C, S, P, and $\left.\mathrm{TiO}_{2}\right) \cdot{ }^{1,2,19-22}$ In 2010, Sun et al. reported that $\mathrm{Ag}$ doped mesoporous $\mathrm{WO}_{3}$, exhibited excellent photocatalytic decomposition of acetaldehyde under visible-light irradiation. ${ }^{1}$ It has been reported that carbon doping enhances 
charges exchange rate and thus improves the photocatalytic activity of $\mathrm{WO}_{3}{ }^{2}$ Furthermore doping may also reduce the band gap of $\mathrm{WO}_{3}$ and improves its photocatalytic efficiency, for instance the band gap of $\mathrm{WO}_{3}$ nanowire array reduced from 2.8 to $2.2 \mathrm{eV}$ after nitridation in a $\mathrm{NH}_{3}$ atmosphere. ${ }^{19}$

Graphene (GR), with a flat monolayer of carbon atoms tightly packed into a two-dimensional honeycomb lattice, is a very promising candidate for high performance photocatalyst because of its high thermal conductivity, ${ }^{23}$ excellent mobility of charge carriers (20000 $\mathrm{cm}^{2} \mathrm{~V}^{-1} \mathrm{~s}^{-1}$ at room temperature), ${ }^{24}$ and a large specific surface area $\left(2630 \mathrm{~m}^{2} \mathrm{~g}^{-1}\right){ }^{25}$ The combination of GR with a well photocatalytic semiconductor is expected to result in a high performance in photocatalytic activity. Recently, there are many reports concerning about incorporation of metal oxide $\left(\mathrm{TiO}_{2}, \mathrm{Sr}_{2} \mathrm{Ta}_{2} \mathrm{O}_{7}\right.$ and $\mathrm{ZnO}$, etc. $)$ on GR sheets to obtain composite photocatalysts. ${ }^{18,26,27}$ It has been shown that GR in the composites could act as electronic conductive channels to improve the electrochemical performance. From the point view of photo-conversion efficiency, the photocatalytic properties of semiconductor could be further enhanced if the recombination of the photoinduced electron-hole pairs can be effectively suppressed. Therefore, the composite consisted of nano $\mathrm{WO}_{3}$ particles and two-dimensional GR sheets is a promising photocatalyst for oxygen production because GR can act as an electron transfer channel thus reducing the recombination of the photo-generated electron holes and leading to improved photoconversion efficiency. ${ }^{3,5,18} \mathrm{Up}$ to now, no investigation concerning about nano $\mathrm{WO}_{3}$ particles on GR sheets for water splitting has been reported. To the best of our knowledge, only one paper concerning about the mixture of $\mathrm{WO}_{3}$ powder and graphene oxide (GO) for in situ reduction under visible light was reported by $\mathrm{Ng}$ et al. But the $\mathrm{WO}_{3}$ particle sizes were really large up to $100 \mathrm{~nm}$ and tended to aggregate during the physical mixing. ${ }^{28}$ How to control the synthesis of crystalline $\mathrm{WO}_{3}$ nanoparticles uniformly on the surface of the GR sheet is critically important. The crystallinity and the particle size of the photocatalyst are two important factors of affecting the photocatalytic activity. ${ }^{6,29-31}$

Herein, we report for the first time the synthesis of a composite $\left(\mathrm{WO}_{3} @ \mathrm{GR}\right)$ consisting of $\mathrm{WO}_{3}$ nanoparticles and GR sheets. The structures and morphologies of the composite were characterized by using a variety of measurements. The photocatalytic oxygen evolution properties of the $\mathrm{WO}_{3} @ \mathrm{GR}$ composite was investigated by measuring the amount of oxygen evolved from water splitting and compared with those of pure $\mathrm{GR}, \mathrm{WO}_{3}$ and the mixture of $\mathrm{WO}_{3}$ and $\mathrm{GR}$ (mixed- $\mathrm{WO}_{3} / \mathrm{GR}$ ).

\section{Experimental}

\section{Preparation of GR}

GR was obtained by chemical reduction of GO which was prepared from natural graphite (crystalline, 300 mesh, Alfa Aesar) by a modified Hummers method. ${ }^{32}$ The details of the preparation of the $\mathrm{GO}$ were described in our previous article. ${ }^{33}$ In a typical reduction experiment, $0.5 \mathrm{~g}$ of $\mathrm{GO}$ powder was dispersed in $150 \mathrm{ml}$ of deionized water and the mixture was sonicated for $1 \mathrm{~h}$. Next, $18 \mathrm{ml}$ of hydrazine (85\%) was added under magnetic stirring, and the mixture was continuously stirred at $50{ }^{\circ} \mathrm{C}$ for $24 \mathrm{~h}$. Finally, black GR powder was obtained by filtration and drying under vacuum at $60{ }^{\circ} \mathrm{C}$.

\section{Preparation of $\mathrm{WO}_{3} @ G R$}

$\mathrm{WO}_{3} @$ GR composite was synthesized by sonochemical reaction of phosphotungstic acid (AR, Sinopharm) in the presence of GO. The process of preparing $\mathrm{WO}_{3} @ \mathrm{GR}$ composite is described as follows: $0.50 \mathrm{~g}$ of $\mathrm{GO}$ was added to $20 \mathrm{ml}$ of $\mathrm{H}_{2} \mathrm{O}$ and stirred for $12 \mathrm{~h}$ under magnetic vigorous stirring at ambient temperature. As the reaction progressed, GO was dissolved in the water, while the mixture gradually became pasty and the color turned into light brownish. At the same time, $1.2 \mathrm{~g}$ of phosphotungstic acid and $10 \mathrm{ml}$ ethanol were mixed uniformity, and slowly added to the above GO mixture. Finally the suspension was sonicated at room temperature for $3 \mathrm{~h}$ using a high-intensity ultrasonic probe (Ti horn, $20 \mathrm{kHz}, 100 \mathrm{~W} \mathrm{~cm}^{-2}$ ). The resulting composite was recovered by centrifugation and rinsed with ethanol solvent and $\mathrm{H}_{2} \mathrm{O}$ several times, then dried under vacuum at $60{ }^{\circ} \mathrm{C}$ to obtain amorphous $\mathrm{WO}_{3}$ and GR composite (A-WO $@$ @GO). After calcination at $550{ }^{\circ} \mathrm{C}$ for $3 \mathrm{~h}$ under nitrogen, black crystallized $\mathrm{WO}_{3} @ \mathrm{GR}$ composite was obtained.

For comparison, pure $\mathrm{WO}_{3}$ powders were also prepared under the same condition without adding GO precursor in the process, and the mixed- $\mathrm{WO}_{3} / \mathrm{GR}$ was prepared by mechanical mixing of pure $\mathrm{WO}_{3}$ and $\mathrm{GR}$, with the same composition as that in the $\mathrm{WO}_{3} @ \mathrm{GR}$ composite.

\section{Characterization}

The synthesized samples were characterized by X-ray diffraction (XRD) using a RigakuD/max2550VL/PC system operated at $40 \mathrm{kV}$ and $40 \mathrm{~mA}$ with $\mathrm{Cu}-\mathrm{K} \alpha$ radiation $(\lambda=1.5406 \AA)$, at a scan rate of $5^{\circ} \mathrm{min}^{-1}$ and a step size of $0.050^{\circ}$ in $2 \theta$. Nitrogen adsorption measurements at $77 \mathrm{~K}$ were performed using an ASAP2020 volumetric adsorption analyzer, after the samples had been outgassed for $8 \mathrm{~h}$ in the degas port of the adsorption apparatus. Field-emission scanning electron microscopy (FESEM) was performed on a JEOL JSM-6360LV field emission microscope at an accelerating voltage of $15 \mathrm{kV}$. Transmission electron microscopy (TEM) and energy-dispersive X-ray measurements (EDX) were carried out on a JEOL 2010 microscope at $200 \mathrm{kV}$. TEM specimens were prepared by grinding the synthesized samples into powder with a mortar and pestle and the powder was dispersed in pure ethanol and picked up with holey carbon supporting films on copper grids. A Dilor LABRAM-1B microspectrometer with $633 \mathrm{~nm}$ laser excitation was used to record the Raman spectrum of the samples. Fourier transform-infrared measurements (FT-IR) were recorded on $\mathrm{KBr}$ pellets with a PE Paragon 1000 spectrophotometer. Thermal gravimetric analysis (TGA) was conducted on a PE TGA-7 instrument with a heating rate of $20{ }^{\circ} \mathrm{C} \min ^{-1}$. Diffuse reflectance electronic spectra (DRS) were measured with a Perkin-Elmer 330 spectrophotometer equipped with a $60 \mathrm{~mm}$ Hitachi integrating sphere accessory.

\section{Photocatalytic oxygen evolution experiments}

Photocatalytic oxidation reactions were conducted at $c a .20{ }^{\circ} \mathrm{C}$ in a Lab Solar gas photocatalysis system with external light irradiation. The light source was a $300 \mathrm{~W}$ high pressure integrated type xenon lamp (PLS-SXE300/300UV, China). Before the photochemical reaction, $60 \mathrm{ml}$ of ultra-pure water 
was degassed by boiling it for $30 \mathrm{~min}$ and cooling to room temperature, and then added it to the reactor. Then $0.05 \mathrm{~g}$ of the photocatalyst (GR, WO $@$ GR, WO $\mathrm{WO}_{3}$ and Mixed-WO $/ \mathrm{GR}$ ) and $10 \mathrm{ml}$ of $16.0 \mathrm{mmol}^{-1} \mathrm{Fe}_{2}\left(\mathrm{SO}_{4}\right)_{3}$ were added to the reactor in tandem under magnetic vigorous stirring to ensure the mixture suspense, using $\mathrm{H}_{2} \mathrm{SO}_{4}$ solution to adjust the $\mathrm{pH}$ of the mixture at 2. During the experiment, the reactor system was filled with flowing temperature-controlled cooling water. The amount of $\mathrm{O}_{2}$ evolved was determined using gas chromatography (GC7890II, thermal conductivity detector, nitrogen carrier gas).

\section{Results and discussions}

The preparation process of the $\mathrm{WO}_{3} @ \mathrm{GR}$ composite is illustrated schematically in Scheme 1. After the dispersion of GO in the aqueous solution, phosphotungstic acid in ethanol was added under continuous stirring. Then the mixture was under ultrasonication for $3 \mathrm{~h}$ to fabricate $\mathrm{WO}_{3}$ on the $\mathrm{GO}$ sheets (A$\left.\mathrm{WO}_{3} @ \mathrm{GO}\right)$. The crystallization of the amorphous $\mathrm{WO}_{3}$ particles and the reduction of the GO to GR were achieved by the calcination of $\mathrm{A}-\mathrm{WO}_{3} @ \mathrm{GO}$ at $550{ }^{\circ} \mathrm{C}$ for $3 \mathrm{~h}$ under nitrogen.

Wide-angle XRD patterns of the pure $\mathrm{WO}_{3}$ powder, A-WO $\mathrm{W}_{3} @ \mathrm{GO}$ and $\mathrm{WO}_{3} @ \mathrm{GR}$ are compared as shown in Fig. 1. The pure $\mathrm{WO}_{3}$ sample is well crystallized in a single phase and all of the diffraction peaks can be indexed to monoclinic $\mathrm{WO}_{3}$ (JCPDF 43-1035). As for the A-WO $@$ GO composite, two broad peaks located at $2 \theta=26.4^{\circ}, 10.6^{\circ}$ were detected, corresponding to graphite carbon and GO with interlayer spacing of $0.34 \mathrm{~nm}$ and $1.02 \mathrm{~nm}$, respectively. ${ }^{34}$ A small peak at $19.5^{\circ}$ is assigned to the residual intermediate of phosphotungstic acid (JCPDF 53-1015). No characteristic peaks of $\mathrm{WO}_{3}$ were presented in the $\mathrm{A}-\mathrm{WO}_{3} @ \mathrm{GO}$ composite before calcination. After calcination at $550{ }^{\circ} \mathrm{C}$, the diffraction peaks which can be indexed to cubic $\mathrm{WO}_{3}$ (JCPDF 20-1324) appeared, indicating the crystalline $\mathrm{WO}_{3}$ formed on the GR sheets. Compared with

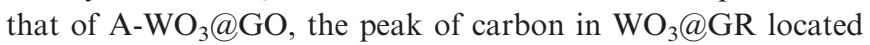
at $26.4^{\circ}$ became distinguished, suggesting the possible reduction of GO to GR occurred during the heat treatment process. This is consistent with the disappearance of the small peak at $2 \theta=10.6^{\circ}$ in the XRD pattern of $\mathrm{WO}_{3} @ \mathrm{GR}$, attributed to the GO in $\mathrm{A}-\mathrm{WO}_{3} @ \mathrm{GO}$. The average particle size of the $\mathrm{WO}_{3}$ in $\mathrm{WO}_{3} @$ GR can be estimated to be around $12 \mathrm{~nm}$ by applying the Scherrer formula. ${ }^{35}$ This result suggests that the growth of nanocrystalline $\mathrm{WO}_{3}$ on the GR sheets was very limited and controlled, which will be further confirmed by TEM.
Fig. 2 shows the TGA of GR and $\mathrm{WO}_{3} @ \mathrm{GR}$ in air by heating up from 40 to $900{ }^{\circ} \mathrm{C}$. The largest weight loss occurs at temperatures from 530 to $690{ }^{\circ} \mathrm{C}$ for both GR and $\mathrm{WO}_{3} @ \mathrm{GR}$, due to the destruction of the carbon skeleton (carbonyl/double bond). The weight loss of $\mathrm{WO}_{3} @$ GR was stabilized at about 40\% at temperatures between 690 and $900{ }^{\circ} \mathrm{C}$, which indicates that the amount of $\mathrm{WO}_{3}$ loaded on the GR sheets was about $60 \mathrm{wt} \%$. It is worth mentioning that a weight loss of $15 \mathrm{wt} \%$ was observed from 150 to $530{ }^{\circ} \mathrm{C}$ for $\mathrm{GR}$, owing to the pyrolysis of the residual hydroxyl group on the surface of GR. Unlike the pure GR sample, only one large weight loss peak at $600{ }^{\circ} \mathrm{C}$ was observed for the $\mathrm{WO}_{3} @ \mathrm{GR}$, illustrating that the $\mathrm{WO}_{3}$ was most likely located on the surface of the supporting GR sheets and didn't form as separate material.

Fig. 3 shows a selected region of the Raman spectra of the pure $\mathrm{WO}_{3}, \mathrm{GR}$ as well as $\mathrm{WO}_{3} @ \mathrm{GR}$. As is expected, GR has two peaks at around 1350 and $1595 \mathrm{~cm}^{-1}$. ${ }^{17}$ The G-band peak at around $1595 \mathrm{~cm}^{-1}$ is characteristic of graphitic sheets, corresponding to a well defined $\mathrm{sp}^{2}$ carbon-type structure. ${ }^{36}$ Whereas, the D-band at around $1350 \mathrm{~cm}^{-1}$ can be attributed to the presence of defects within the hexagonal graphitic structure. ${ }^{37}$ Thus a smaller $\mathrm{I}_{\mathrm{D}} / \mathrm{I}_{\mathrm{G}}$ peak intensity ratio of a Raman spectrum indicates lower defects and disorders of the graphitized structures. Similar peaks at D-band $\left(1366 \mathrm{~cm}^{-1}\right)$ and G-band $\left(1640 \mathrm{~cm}^{-1}\right)$ are also observed in the $\mathrm{WO}_{3} @ \mathrm{GR}$ composite. From the spectra in Fig. 3, we can see that the $I_{D} / I_{G}$ ratio decreases from 1.16 for the GR sheets to 0.75 for the $\mathrm{WO}_{3} @ \mathrm{GR}$ composite. The higher $\mathrm{I}_{\mathrm{D}} / \mathrm{I}_{\mathrm{G}}$ ratio of the $\mathrm{GR}$ is probably due to the formation of large number of multilayered GR (thin graphite) through GR restacking. The GR restacking in the $\mathrm{WO}_{3} @$ GR composite would be much reduced because the GR surfaces were coated with $\mathrm{WO}_{3}$. Consequently the $\mathrm{WO}_{3} @ \mathrm{GR}$ composite has less lattice defects than the GR reduced from the GO. The smaller number of the defects will benefit to the photocatalytic activity of the WO $\mathrm{WO}_{3} @ \mathrm{GR}$ composites because these lattice defects normally act as recombination centers for the photo-generated electrons and holes. Moreover, Raman vibrations centered at 129, 276, 709, $801 \mathrm{~cm}^{-1}$ characteristic of pure $\mathrm{WO}_{3}$ were also detected in the sample of $\mathrm{WO}_{3} @ \mathrm{GR}$ composite. These bands are due to the stretching mode $\mathrm{O}-\mathrm{W}-\mathrm{O}$. Compared with that of the pure $\mathrm{WO}_{3}$ powder, the band at $709 \mathrm{~cm}^{-1}$ attributed to $\mathrm{W}=\mathrm{O}$ bonds was broadened and shifted to $678 \mathrm{~cm}^{-1}$ for the $\mathrm{WO}_{3}$ in the $\mathrm{WO}_{3} @ \mathrm{GR}$ composite, probably because the formation of $\mathrm{C}-\mathrm{O}-\mathrm{W}$ bonds makes the initial $\mathrm{W}=\mathrm{O}$ bond weaker and a similar phenomena has been reported

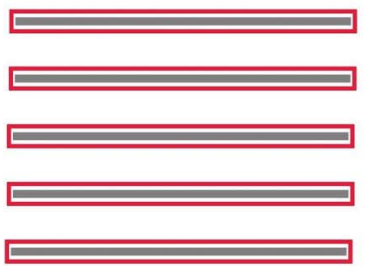

Graphene Oxide (GO)

phosphotungstic acid
Ethanol

Sonochemical

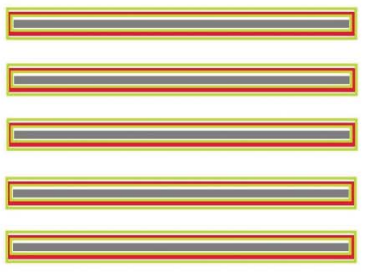

Intermedium (A-WO $\mathrm{W}_{3}$ GO)

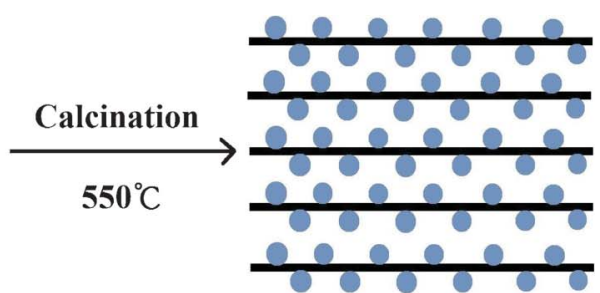

WO3@GR

Scheme 1 Synthetic procedure for the preparation of $\mathrm{WO}_{3} @$ GR composite. 


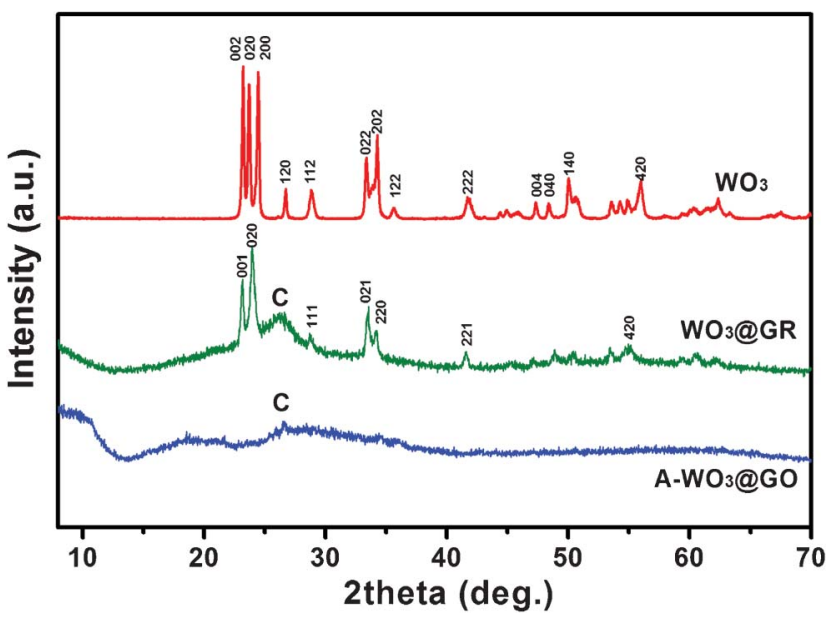

Fig. 1 XRD of $\mathrm{WO}_{3}, \mathrm{~A}-\mathrm{WO}_{3} @ \mathrm{GO}$ and $\mathrm{WO}_{3} @ \mathrm{GR}$.

elsewhere. ${ }^{38}$ This means that $\mathrm{WO}_{3}$ was grafted onto the surface of GR layer via $\mathrm{C}-\mathrm{O}-\mathrm{W}$ bonds rather physically adsorbed on the GR sheets. This kind of structure is desirable for charge transfer upon light excitation. ${ }^{39}$ It is worth noting that a G-band up-shift from 1595 to $1604 \mathrm{~cm}^{-1}$ was observed for $\mathrm{WO}_{3} @$ GR compared with GR. This G-band up-shift is generally an evidence of chemical doping of carbon materials. The trend was similar to previous studies with the p-type doping of the GR causing upshift of the G-band. ${ }^{40}$ The Raman G-band shift provides reliable evidence of charge transfer between the GR sheets and the $\mathrm{WO}_{3}$ in the $\mathrm{WO}_{3} @ \mathrm{GR}$ composite and suggests a dyadic bonding between the GR and $\mathrm{WO}_{3}$.

The interaction between the $\mathrm{WO}_{3}$ and $\mathrm{GR}$ was also confirmed by FT-IR spectroscopy as shown in Fig. 4. C-O functionalities such as $\mathrm{COOH}\left(1724.8 \mathrm{~cm}^{-1}\right)$ and $\mathrm{C}-\mathrm{OH}\left(1045.3 \mathrm{~cm}^{-1}\right)$ are clearly visible in the $\mathrm{GO}$. The spectrum also shows a $\mathrm{C}=\mathrm{C}$ peak at $1606.3 \mathrm{~cm}^{-1}$ corresponding to the remaining $\mathrm{sp}^{2}$ character. As for $\mathrm{A}-\mathrm{WO}_{3} @ \mathrm{GO}$, the broad absorptions at low frequencies were ascribed to the vibration of $\mathrm{W}-\mathrm{O}-\mathrm{W}$ bond (below $1000 \mathrm{~cm}^{-1}$ ) which was not observed in the spectrum of GO. It was found that the peak of the $\mathrm{C}-\mathrm{OH}$ at $1045.3 \mathrm{~cm}^{-1}$ for $\mathrm{GO}$ shifted to a higher

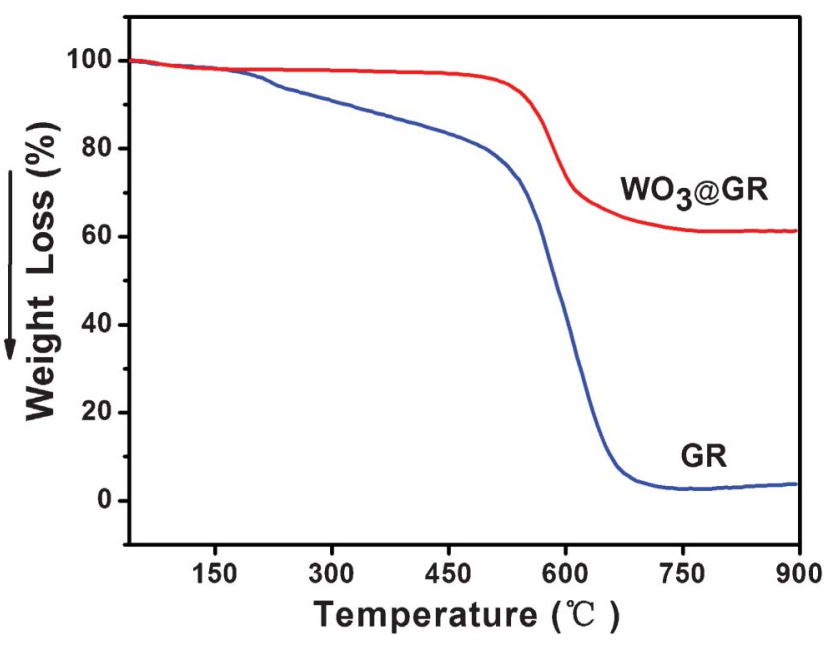

Fig. 2 TGA curves of GR and $\mathrm{WO}_{3} @ \mathrm{GR}$ (heating rate $=20{ }^{\circ} \mathrm{C} \mathrm{min}^{-1}$ under air atmosphere).

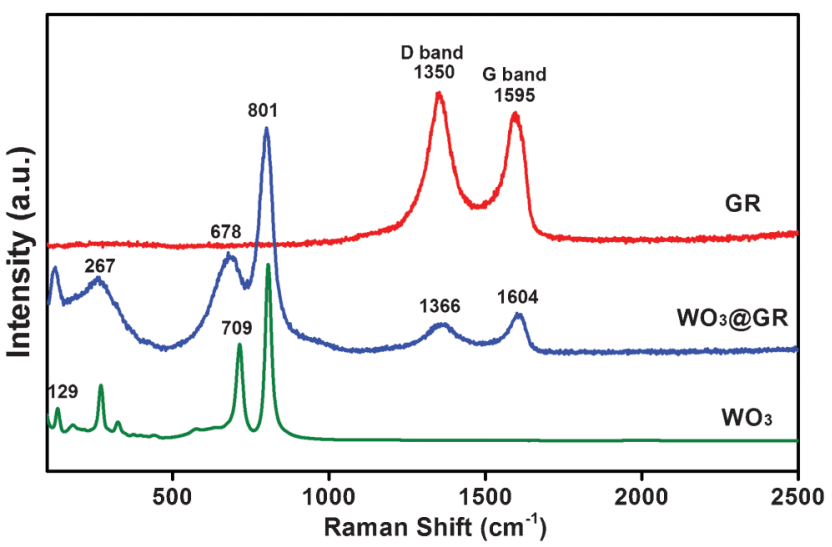

Fig. 3 Raman spectra of pure $\mathrm{WO}_{3}, \mathrm{GR}$ and $\mathrm{WO}_{3} @ \mathrm{GR}$.

wave number of $1079 \mathrm{~cm}^{-1}$ for A-WO $@ \mathrm{GO}$, which could be explained by the influence of the formation of $\mathrm{C}-\mathrm{O}-\mathrm{W}$ bond.

SEM images of GR, A- $\mathrm{WO}_{3} @ \mathrm{GO}$ and $\mathrm{WO}_{3} @ \mathrm{GR}$ are shown in Fig. 5. The pure GR has a layered structure with a very smooth surface (Fig. 5a and b), while the A-WO $@$ GO and $\mathrm{WO}_{3} @$ GR composite shows a mass of wrinkles (Fig. 5c-f). The layered structure of the GR sheets in the $\mathrm{WO}_{3} @ \mathrm{GR}$ composite exhibits nanoscale textures, indicative of a much rougher surface. In addition a large amount of $\mathrm{WO}_{3}$ nanoparticles were observed clearly dispersion on both the GR surface and the interlayers without apparent agglomeration (Fig. 5e). Fig. 5f shows that the particle size is very uniform with tens nanometres in diameters, illustrating that ultrasonic sound irradiation is an effective method of fabricating $\mathrm{WO}_{3}$ nanoparticles on the GR surface.

The structures and composition of the $\mathrm{WO}_{3} @ \mathrm{GR}$ composite were further characterized by using TEM and EDX, and the results are shown in Fig. 6. From the low-resolution TEM (Fig. 6a), it can be seen there are plenty of wrinkles on the clean sheet owing to the two-dimensional nature of the matrix sheet. From the high resolution image, discrete and well defined $\mathrm{WO}_{3}$ particles are uniformly scattered on the sheets with the particle size of around $12 \mathrm{~nm}$ (Fig. 6b). This observation is consistent with the wide angle XRD results presented in Fig. 1. As demonstrated in Fig. 6c, the measured lattice-fringe spacing of

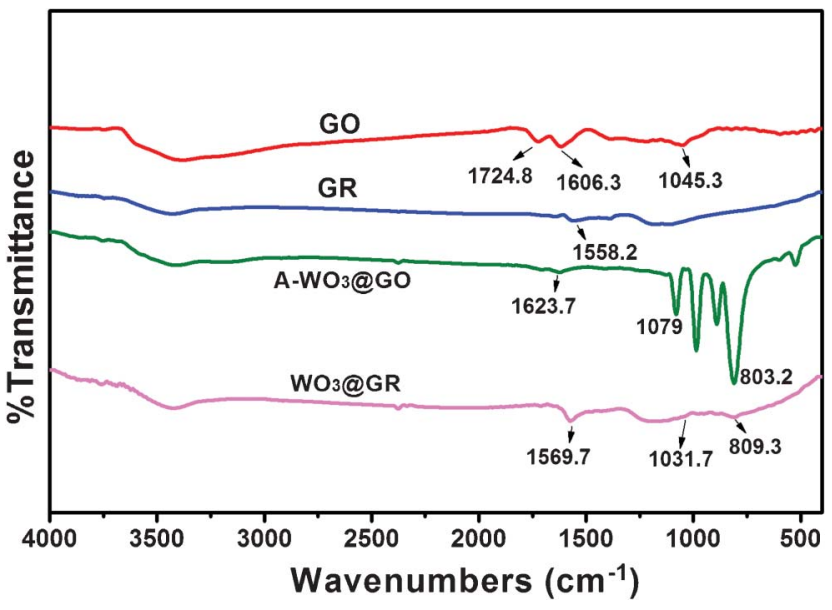

Fig. 4 FT-IR spectra of GO, GR, A-WO $@$ @ GO and WO $@$ @GR. 

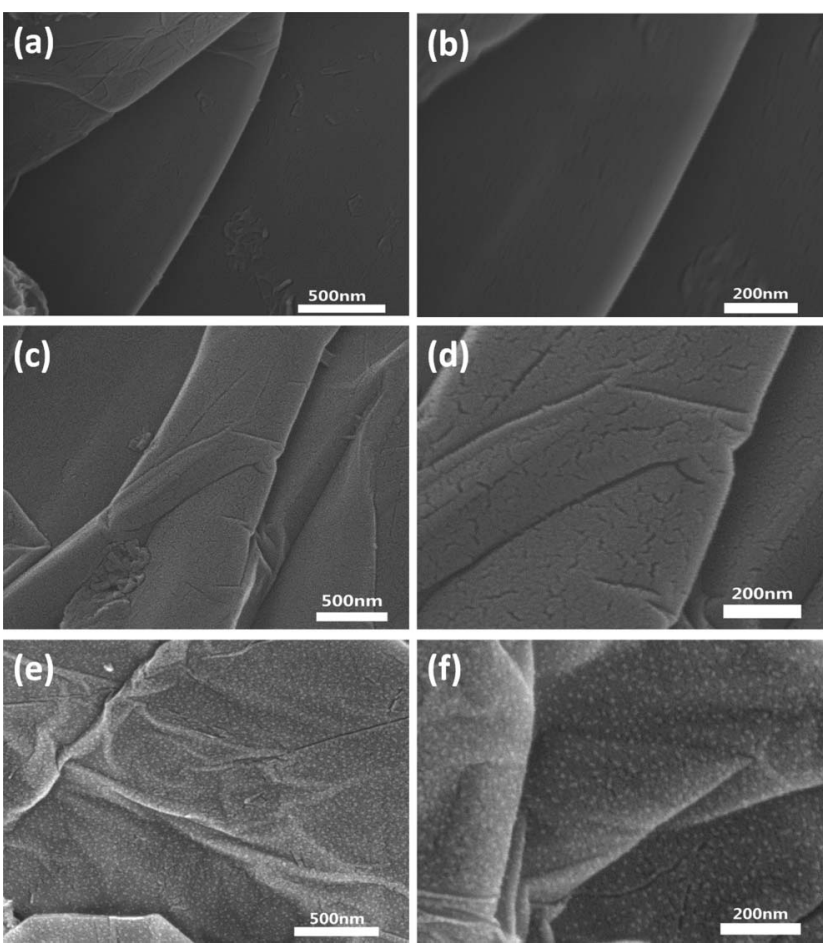

Fig. 5 FE-SEM images of GR (a, b), A-WO $\mathrm{W}_{3} @ \mathrm{GO}(\mathrm{c}, \mathrm{d})$ and $\mathrm{WO}_{3} @ \mathrm{GR}(\mathrm{e}, \mathrm{f})$ in different magnifications.
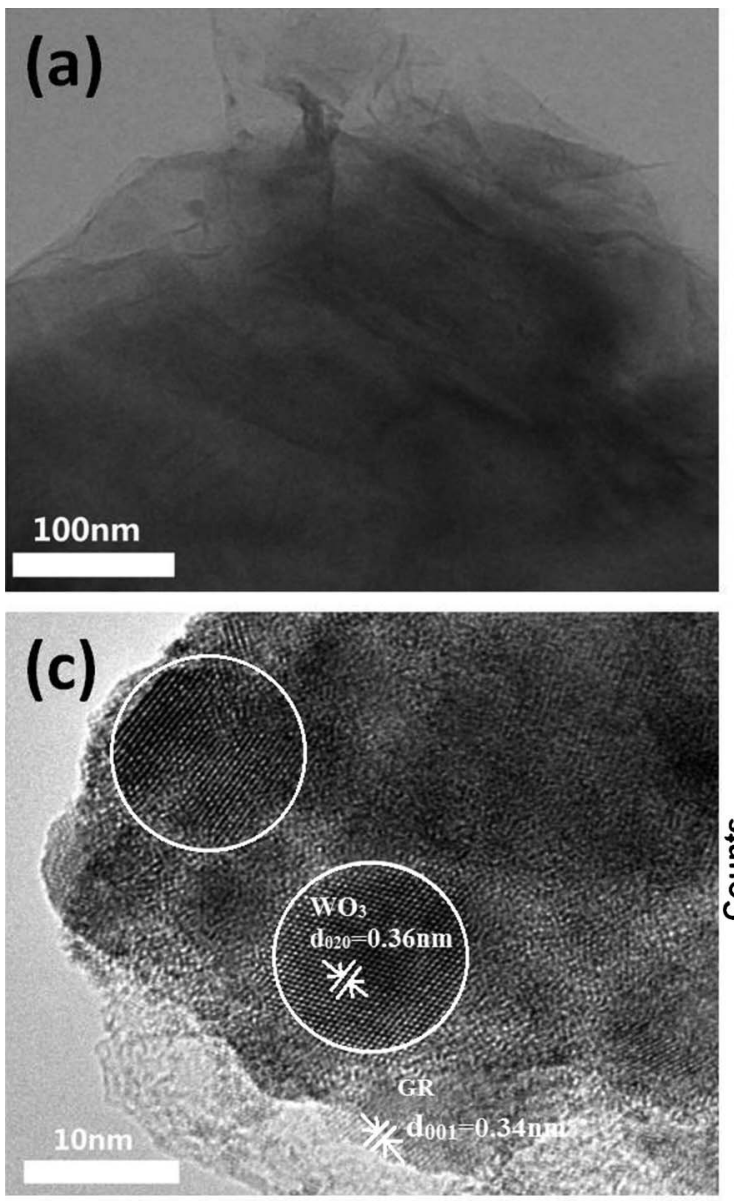

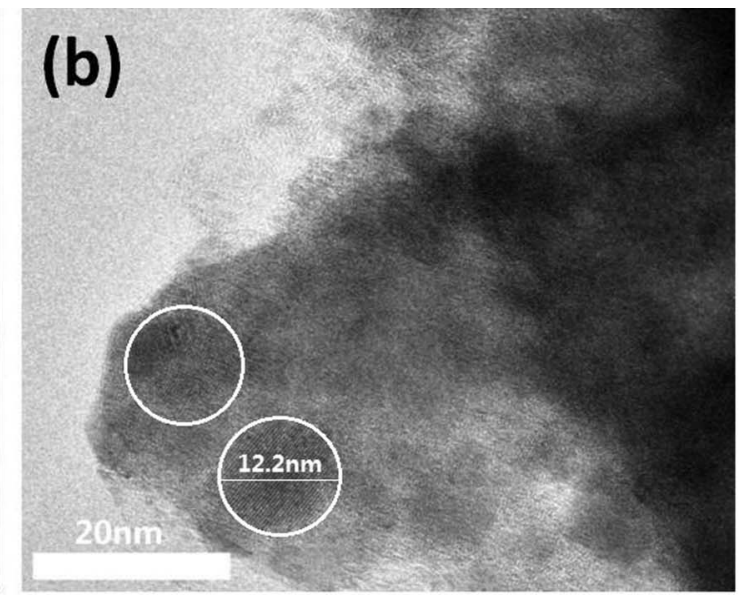

$0.34 \mathrm{~nm}$ in the ribbons was detected corresponding to the (001) of the GR sheets; and the measured lattice fringe spacing of $0.36 \mathrm{~nm}$ in $\mathrm{WO}_{3} @ \mathrm{GR}$ composites corresponds to the $(020)$ of cubic $\mathrm{WO}_{3}$ (JCPDF 20-1324). Fig. 6 shows the EDX spectrum from the area shown in Fig. 6c. The TEM results provide the direct evidence of $\mathrm{WO}_{3}$ nanoparticles on the surface of GR sheets.

$\mathrm{N}_{2}$ adsorption/desorption isotherms of the samples $\mathrm{WO}_{3}$ and $\mathrm{WO}_{3} @$ GR have been measured and are shown in Fig. 7. Both of the $\mathrm{WO}_{3}$ and $\mathrm{WO}_{3} @ \mathrm{GR}$ samples show similar isotherm curves. The $\mathrm{WO}_{3}$ sample has a specific surface area of $7.29 \mathrm{~m}^{2} \mathrm{~g}^{-1}$ according to the BET (Brunauer, Emmett and Teller) analysis and the specific surface area of the $\mathrm{WO}_{3} @$ GR samples is $20.72 \mathrm{~m}^{2} \mathrm{~g}^{-1}$. The increase of the surface area can be explained by the special structure of GR which has ordered two-dimensional honeycomb lattice and a large specific surface area (GR, $\left.66.35 \mathrm{~m}^{2} \mathrm{~g}^{-1}\right)$.

The light-absorbance properties of the pure $\mathrm{WO}_{3}, \mathrm{GR}$ and $\mathrm{WO}_{3} @$ GR composite were studied with a UV-vis spectrophotometer and the obtained spectra are shown in Fig. 8. Both the GR and $\mathrm{WO}_{3} @ \mathrm{GR}$ show a similar spectrum shape with strong adsorption from UV to visible light region because their similar black appearance. At a wavelength above $500 \mathrm{~nm}$ the pure $\mathrm{WO}_{3}$ has a much weaker absorption and different shape in comparison with those of the GR and $\mathrm{WO}_{3} @ \mathrm{GR}$ samples. As shown in Fig. 8, the light absorption intensity of $\mathrm{WO}_{3} @ \mathrm{GR}$ is stronger than that of GR due to the presence of $60 \mathrm{wt} \% \mathrm{WO}_{3}$ in the $\mathrm{WO}_{3} @ \mathrm{GR}$ composite. At the same time, the light absorption

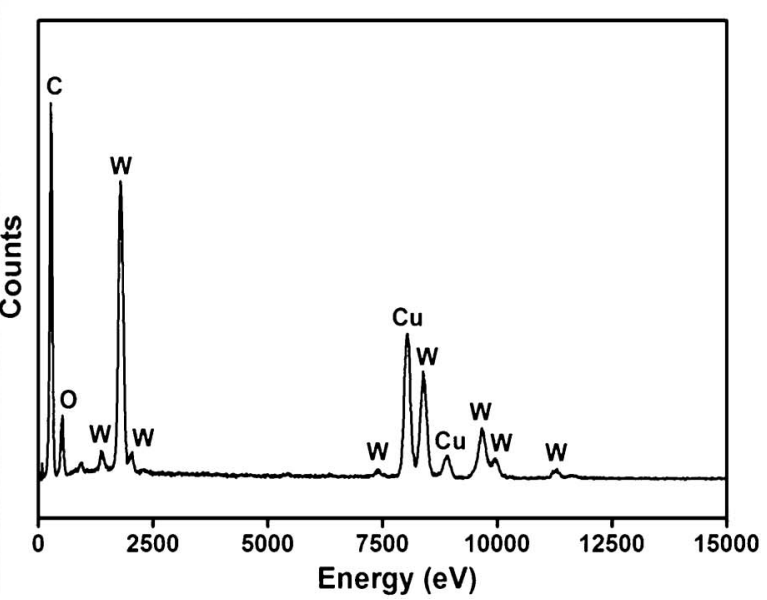

Fig.6 TEM images of $\mathrm{WO}_{3} @ \mathrm{GR}$ in different resolutions (a, b, and c) and EDX images. 


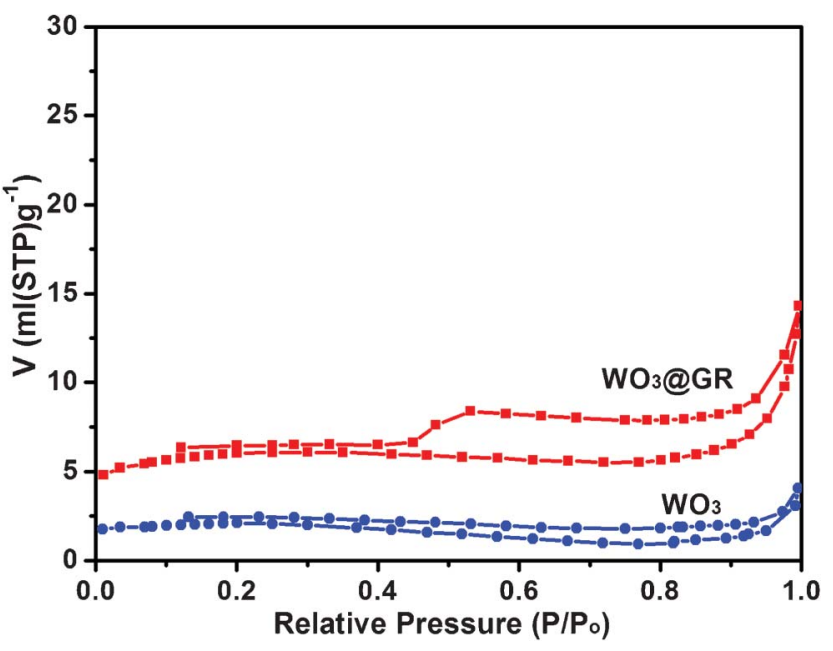

Fig. $7 \mathrm{~N}_{2}$ adsorption/desorption isotherms of samples $\mathrm{WO}_{3}$ and $\mathrm{WO}_{3} @ \mathrm{GR}$.

intensity of $\mathrm{WO}_{3} @ \mathrm{GR}$ is also much stronger than that of $\mathrm{WO}_{3}$ in visible light range resulting from the existence of $40 \mathrm{wt} \% \mathrm{GR}$ in the $\mathrm{WO}_{3} @ \mathrm{GR}$ composite. DRS demonstrate the synergistic effect of $\mathrm{GR}$ and $\mathrm{WO}_{3}$ contributed to an improved light harvesting property. This is expected to result in an improved photocatalytic activity over the complete spectral range.

The photocatalytic activities of the $\mathrm{WO}_{3} @ \mathrm{GR}$, pure GR, pure $\mathrm{WO}_{3}$ and mixed- $\mathrm{WO}_{3} / \mathrm{GR}$ in terms of $\mathrm{O}_{2}$ generation from water were measured using a Lab Solar gas photocatalysis system with external light irradiation and the results are shown in Fig. 9. In order to remove the gas dissolved in water, before the photochemical reaction, ultra-pure water was boiled for $30 \mathrm{~min}$ and cooled to room temperature. Fig. 9 shows the amount of evolved $\mathrm{O}_{2}$ of photocatalyst $\left(\mathrm{GR}, \mathrm{WO}_{3}\right.$, mixed- $\mathrm{WO}_{3} / \mathrm{GR}$ and $\left.\mathrm{WO}_{3} @ \mathrm{GR}\right)$ by solar light from an aqueous solution containing the $\mathrm{Fe}^{3+}$ ion as an electron acceptor. The amount of evolved $\mathrm{O}_{2}$ from the aqueous solution after $9 \mathrm{~h}$ for the $\mathrm{WO}_{3} @ \mathrm{GR}$ was $c a$. $388 \mu \mathrm{mol} \mathrm{L}^{-1}$, which is more than 1.8 times and twice as much as

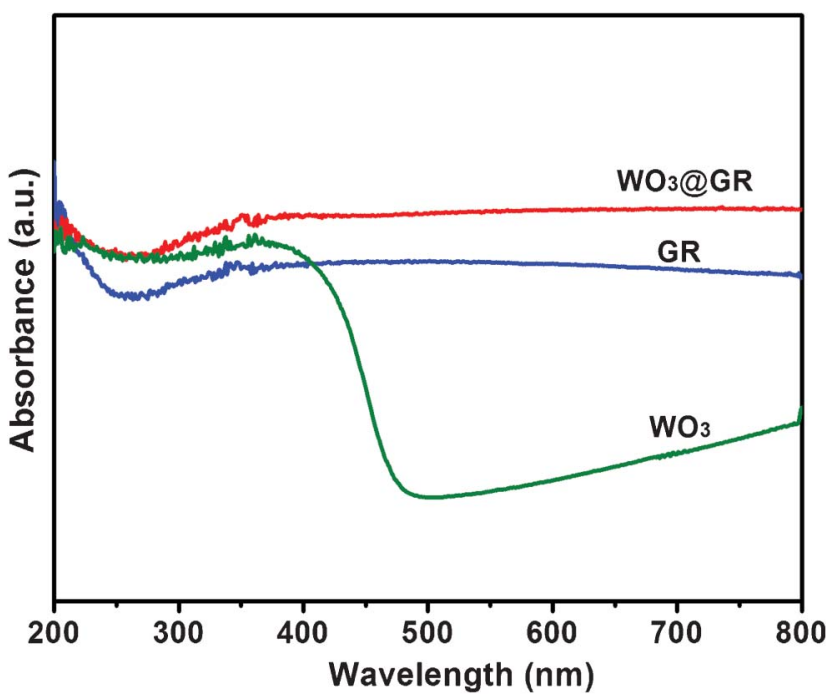

Fig. 8 Diffuse reflectance electronic spectra of pure $\mathrm{WO}_{3}, \mathrm{GR}$ and $\mathrm{WO}_{3} @ \mathrm{GR}$.

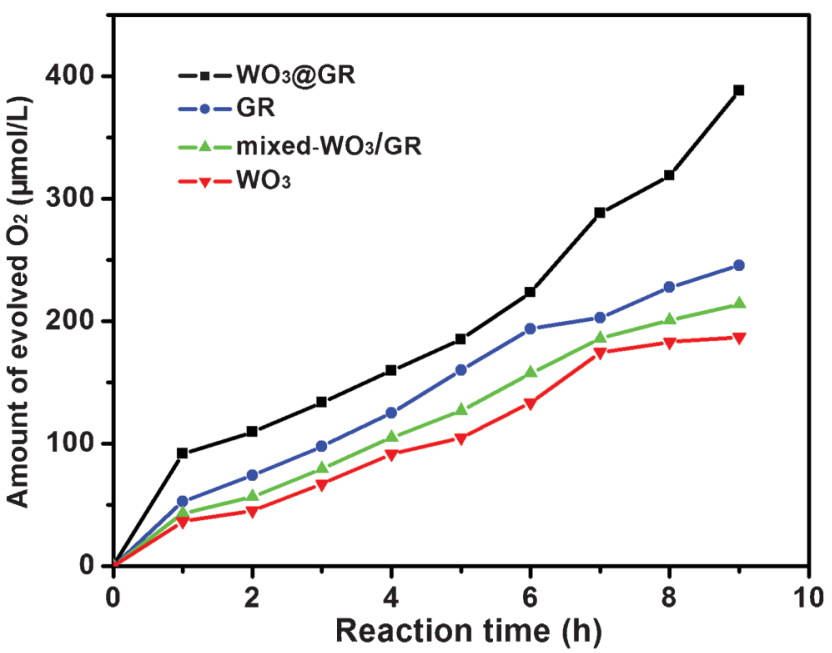

Fig. 9 Time course of $\mathrm{O}_{2}$ evolution from the solution with suspended photocatalyst $\left(\mathrm{WO}_{3}, \mathrm{GR}\right.$, mixed- $\mathrm{WO}_{3} / \mathrm{GR}$ and $\left.\mathrm{WO}_{3} @ \mathrm{GR}\right)$ under xenon lamp irradiation.

that of the mixed-WO $\mathrm{WO}_{3} / \mathrm{GR}\left(\mathrm{ca} .214 \mu \mathrm{mol} \mathrm{L}{ }^{-1}\right.$ ) and $\mathrm{WO}_{3}$ (ca. $186 \mu \mathrm{mol} \mathrm{L}{ }^{-1}$ ), respectively.

In our photocatalytic oxygen evolution experiments, illumination photons create electron-hole pairs in the $\mathrm{WO}_{3}$ at the solidsolution interface (eqn 1). These electron-hole pairs separate and reach to the photocatalyst surface by diffusion. $\mathrm{WO}_{3}$ is photocatalyst with weak reducing power owing to their positive conduction band position $(>0 \mathrm{eV} v s$. NHE at $\mathrm{pH}=0)$, which prohibits the electron transfer to reduce $\mathrm{H}_{2} \mathrm{O}$ to $\mathrm{H}_{2}{ }^{41}$ Therefore, only holes reaction with water to produce $\mathrm{O}_{2}$ can occur spontaneously by using these photocatalyst (eqn 2). However, electron-hole pairs are very easily to recombine either with defect and trap states or within grain boundaries quickly, which diminishes the efficiency of the photocatalytic reaction significantly. Generally, a scavenger is used to reduce the recombination of electron-hole pairs in order to enhance charge transport rate and improve photocatalytic activity. Here, $\mathrm{Fe}_{2}\left(\mathrm{SO}_{4}\right)_{3}$ was used as the scavenger. The $\mathrm{Fe}^{3+}$ ion would react with photoinduced electrons as an electron acceptor to reduce the recombination of electron-hole pairs (eqn 3).

$$
\begin{gathered}
h v \stackrel{\text { Photocatalyst }}{\longrightarrow} e^{-}+h^{+} \\
2 \mathrm{H}_{2} \mathrm{O}+4 h^{+} \rightarrow 4 \mathrm{H}^{+}+\mathrm{O}_{2} \\
4 \mathrm{~F}_{\mathrm{e}}^{3+}+4 e^{-} \rightarrow 4 \mathrm{~F}_{\mathrm{e}}{ }^{2+}
\end{gathered}
$$

The total equation for the photocatalytic $\mathrm{O}_{2}$ production may be summarized in the following:

$$
2 \mathrm{H}_{2} \mathrm{O}+4 \mathrm{Fe}^{3+} \underset{\text { Photocatalyst }}{\stackrel{h v}{\longrightarrow}} 4 \mathrm{Fe}^{2+}+4 \mathrm{H}^{+}+\mathrm{O}_{2}
$$

It should be noted that the amount of evolved $\mathrm{O}_{2}$ from mixed$\mathrm{WO}_{3} / \mathrm{GR}\left(60 \mathrm{wt} \% \mathrm{WO}_{3}\right.$ and $40 \mathrm{wt} \%$ GR) was measured about $214 \mu \mathrm{mol} \mathrm{L} \mathrm{L}^{-1}$, which was much lower than that from the obtained $\mathrm{WO}_{3} @ \mathrm{GR}$ composite $\left(388 \mu \mathrm{mol} \mathrm{L}{ }^{-1}\right)$. The difference could be mainly due to the structure of the $\mathrm{WO}_{3} @ \mathrm{GR}$ composite. The chemical bonds $(\mathrm{C}-\mathrm{O}-\mathrm{W}$ etc. $)$ between $\mathrm{WO}_{3}$ 
and GR sheets suggested by the shift of Raman peak and FT-IR (Fig. 3 and Fig. 4), which do not only enhance the optical adsorption by sensitizing the $\mathrm{WO}_{3}$ in visible light, but also significantly enhance charge separation efficiency and carrier transfer rate. A similar phenomenon has also been observed by Zhao et al. in the carbon@ $\mathrm{TiO}_{2}$ with a "dyade" structure. ${ }^{5}$ The enhanced visible-light absorption was explained as the surface nanometre carbon materials which can show collective polarization modes and sensitize semiconductors.

GR has a charge-carrier mobility of $20000 \mathrm{~cm}^{2} \mathrm{~V}^{-1} \mathrm{~s}^{-1}$, so it is very possible that the incorporation of GR might enhance the charge separation efficiency and suppress the charge recombination as suggested by Scheme 2. Under visible light illumination, electrons in the valence band (VB) acquire enough energy and jump into the conduction band $(\mathrm{CB})$ of $\mathrm{WO}_{3}$, leaving positive charged holes in the VB. GR with a two-dimensional conjugated $\pi-\pi$ graphitic carbon network and superior electrical conductivity could efficiently transfer the photo-generated electrons away from the $\mathrm{WO}_{3}$. Finally, the electrons were quickly scavenged by the electron acceptor of $\mathrm{Fe}^{3+}$ in the solution, ${ }^{42}$ while the holes in the $\mathrm{VB}$ reacted with $\mathrm{H}_{2} \mathrm{O}$ to produce $\mathrm{O}_{2}$. Thus $\mathrm{GR}$ served as an acceptor of the $\mathrm{CB}$ electrons of the $\mathrm{WO}_{3}$ and effectively suppressed the charge recombination in $\mathrm{WO}_{3} @ \mathrm{GR}$ sample, leaving more positive charged holes on the $\mathrm{WO}_{3}$ surface and thus promoting the production of oxygen. ${ }^{43,44}$

Zhang et al. reported that the photocatalytic activity would decrease distinctly with the content of GR exceeding $5 \mathrm{wt} \%$ in $\mathrm{GR} / \mathrm{TiO}_{2}$ composite by introducing electron-hole recombination centers into the composite. ${ }^{18}$ Surprisingly, in our case the percentage of GR in $\mathrm{WO}_{3} @ \mathrm{GR}$ nanocomposite reached as high as $40 \mathrm{wt} \%$, it still showed an enhanced photocatalytic activity (Fig. 9). It could be explained by the bonds between the GR and $\mathrm{WO}_{3}$ in the $\mathrm{WO}_{3} @ \mathrm{GR}$ composite. Carboxylic species of the GO interacting with the precursor of the $\mathrm{WO}_{3}$ particles enable the dispersion and adhesion of particles onto the GO as suggested by Raman and FT-IR measurements. The close contact and bonds would enable easy charge transfer between the $\mathrm{WO}_{3}$ particles and GR sheets. As evidenced by the $\mathrm{I}_{\mathrm{D}} / \mathrm{I}_{\mathrm{G}}$ ratios in the Raman spectra, the GR in $\mathrm{WO}_{3} @ \mathrm{GR}$ composite contains less lattice defects than the stand alone GR so that the electron-hole recombination rate would be much lower for the $\mathrm{WO}_{3} @ \mathrm{GR}$

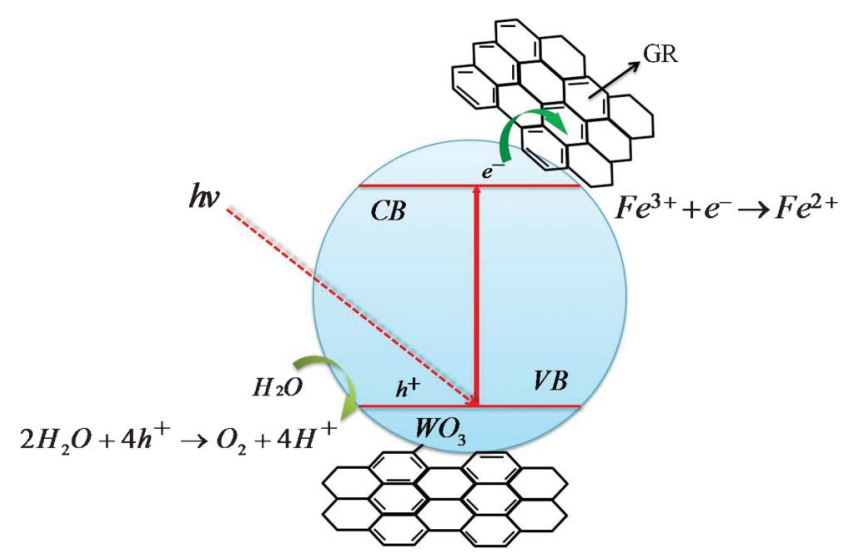

Scheme 2 The procedure of photocatalytic oxidation for the $\mathrm{WO}_{3} @ \mathrm{GR}$ composite. composite. In Zhang's case, there is no chemical bond between the mixed GR and powder $\mathrm{TiO}_{2}$ so that the interface boundaries become the recombination centers for electrons and holes.

Furthermore, the crystallinity and the particle size of the photocatalyst are also important factors to the photocatalytic activity. ${ }^{6,30,31}$ The higher the crystalline quality of the $\mathrm{WO}_{3}$ is, the less amount of defects it has. Defects can operate as recombination centers between the $\mathrm{CB}$ electrons and VB holes and reduce the photocatalytic activity. The smaller the particle size is, the shorter time need for electron-hole pairs moving from inner to surface, which will decrease the electron-hole pairs recombination and enhance the photocatalytic activity. Clearly the photocatalytic activity of the $\mathrm{WO}_{3} @ \mathrm{GR}$ composites is much better than both the pure $\mathrm{WO}_{3}$ and the mixed- $\mathrm{WO}_{3} / \mathrm{GR}$ due to the synergistic effects from $\mathrm{WO}_{3}$ and $\mathrm{GR}$ in the photocatalytic process.

The same process has been extended to the fabrication of $\mathrm{Bi}_{2} \mathrm{WO}_{6}$ on the surface of GR sheets $\left(\mathrm{GR}-\mathrm{Bi}_{2} \mathrm{WO}_{6}-\mathrm{T}\right)$. As is expected, the combination of functionality of $\mathrm{Bi}_{2} \mathrm{WO}_{6}$ with the unique properties of GR results in an improved performance in $\mathrm{O}_{2}$ production from water splitting (Fig. 10). Therefore, this methodology opens up a new way of obtaining photoactive GR-semiconductor composites for photodissociating water under visible light.

\section{Conclusions}

$\mathrm{WO}_{3} @$ GR composite, a visible light photocatalyst, was successfully synthesized using a sonochemical method in a short time. SEM and TEM provided direct evidence that a fine and uniform distribution of $\mathrm{WO}_{3}$ nanoparticles formed on the surface of GR sheets. The average particle size of the $\mathrm{WO}_{3}$ was controlled at around $12 \mathrm{~nm}$ on the GR sheets without using any surfactant. When used as photocatalyst for water splitting, the amount of evolved $\mathrm{O}_{2}$ from $\mathrm{WO}_{3} @ \mathrm{GR}$ with 40 wt $\%$ GR inside is much higher than that of pure $\mathrm{WO}_{3}$ and mixed- $\mathrm{WO}_{3} / \mathrm{GR}, 1.8$ times and 2 times as much as that from mixed-WO $/ \mathrm{GR}\left(c a .214 \mu \mathrm{mol} \mathrm{L}^{-1}\right)$ and pure $\mathrm{WO}_{3}\left(c a .186 \mu \mathrm{mol} \mathrm{L}{ }^{-1}\right)$, respectively. The improved performance is due to the synergistic effects of chemically bonded $\mathrm{WO}_{3}$ and GR. The sensitization of $\mathrm{WO}_{3}$ by GR enhanced the

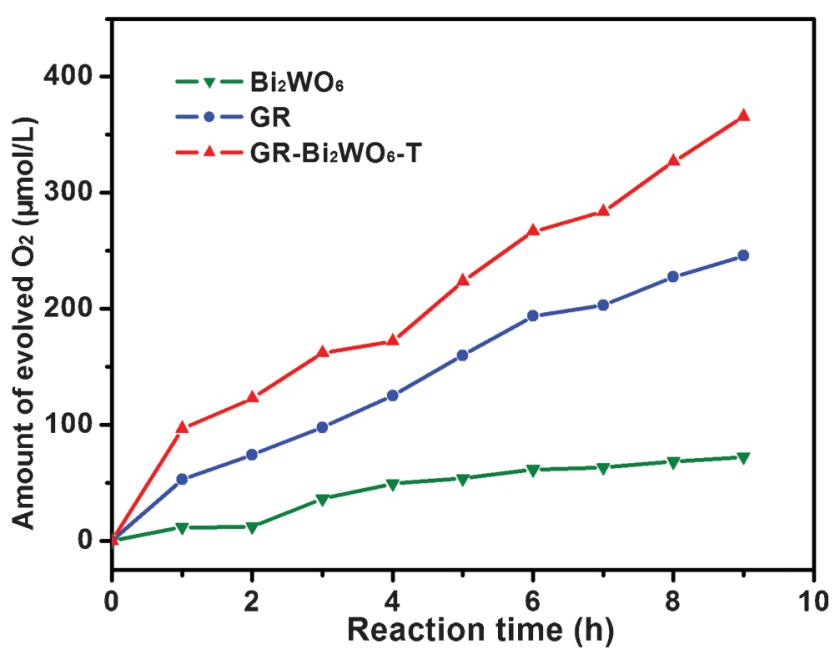

Fig. 10 Time course of $\mathrm{O}_{2}$ evolution from the solution with suspended photocatalyst $\left(\mathrm{Bi}_{2} \mathrm{WO}_{6}, \mathrm{GR}\right.$ and $\left.\mathrm{GR}-\mathrm{Bi}_{2} \mathrm{WO}_{6}-\mathrm{T}\right)$ under xenon lamp irradiation. 
visible light absorption property of $\mathrm{WO}_{3} @ \mathrm{GR}$. The chemical bonding between $\mathrm{WO}_{3}$ and GR reduced the recombination of the photo-generated electron-hole pairs, leading to improved photoconversion efficiency. This simple strategy opens up a new way to design more optimized systems for photodissociating water under visible light.

\section{Acknowledgements}

The authors gratefully acknowledge the financial support of this research by the National Science Foundation of China (Nos. 51072117, 50772067, 51131004, 51171110, 2012CB619600), Shanghai Science and Technology Committee (No. 10JC1407600), and Sino-French Project of MOST of China (No. 2009DFA52410), Shanghai Jiao Tong University Innovation Fund for Postgraduates and KBSI grant (T31903) to W.-J. Moon. We also thank SJTU Instrument Analysis Center for the measurements.

\section{References}

1 S. M. Sun, W. Z. Wang, S. Z. Zeng, M. Shang and L. Zhang, J. Hazard. Mater., 2010, 178, 427.

2 H. T. Zheng and M. Mathe, Int. J. Hydrogen Energy, 2011, 36, 1960.

3 H. Zhang, X. J. Lv, Y. M. Li, Y. Wang and J. H. Li, ACS Nano, $2010,4,380$

4 J. He, Q. Z. Cai, Q. Luo, D. Q. Zhang, T. T. Tang and Y. F. Jiang, Korean J Chem Eng, 2010, 27, 435.

5 L. Zhao, X. F. Chen, X. C. Wang, Y. J. Zhang, W. Wei, Y. H. Sun, M. Antonietti and M. M. Titirici, Adv. Mater., 2010, 22, 3317.

6 Z. K. Cui, D. W. Zeng, T. T. Tang, J. Liu and C. S. Xie, J. Hazard. Mater., 2010, 183, 211.

7 Z. G. Zhao and M. Miyauchi, Angew. Chem., Int. Ed., 2008, 47, 7051.

8 T. F. Jaramillo, S. H. Baeck, A. Kleiman-Shwarsctein and E. W. McFarland, Macromol. Rapid Commun., 2004, 25, 297.

9 Y. F. Qiu, M. L. Yang, H. B. Fan, Y. Z. Zuo, Y. Y. Shao, Y. J. Xu, X. X. Yang and S. H. Yang, CrystEngComm, 2011, 13, 1843.

10 L. Zhou, W. Z. Wang, H. L. Xu, S. M. Sun and M. Shang, Chem.Eur. J., 2009, 15, 1776.

11 M. Ikeda, Y. Kusumoto, S. Somekawa, P. Ngweniform and B. Ahmmad, J. Photochem. Photobiol., A, 2006, 184, 306.

12 T. Maschmeyer and M. Che, Angew. Chem., Int. Ed., 2010, 49, 1536.

13 N. L. Wu, M. S. Lee, Z. J. Pon and J. Z. Hsu, J. Photochem. Photobiol., A, 2004, 163, 277.

14 Y. F. Guo, X. Quan, N. Lu, H. M. Zhao and S. Chen, Environ. Sci. Technol., 2007, 41, 4422.

15 J. G. Yu, L. F. Qi, B. Cheng and X. F. Zhao, J. Hazard. Mater., 2008, 160, 621.

16 G. R. Bamwenda and H. Arakawa, Appl. Catal., A, 2001, 210, 181.
17 E. P. Gao, W. Z. Wang, M. Shang and J. H. Xu, Phys. Chem. Chem. Phys., 2011, 13, 2887.

18 X. Y. Zhang, H. P. Li, X. L. Cui and Y. H. Lin, J. Mater. Chem., 2010, 20, 2801.

19 V. Chakrapani, J. Thangala and M. K. Sunkara, Int. J. Hydrogen Energy, 2009, 34, 9050.

20 B. W. Mwakikunga, A. Forbes, E. Sideras-Haddad, M. Scriba and E. Manikandan, Nanoscale Res. Lett., 2010, 5, 389.

21 L. F. Cheng, X. T. Zhang, B. Liu, H. Z. Wang, Y. C. Li, Y. B. Huang and Z. L. Du, Nanotechnology, 2005, 16, 1341.

22 L. L. Cao, J. Yuan, M. X. Chen and W. F. Shangguan, J. Environ. Sci., 2010, 22, 454.

23 A. K. Geim and K. S. Novoselov, Nat. Mater., 2007, 6, 183.

24 A. Dato, V. Radmilovic, Z. H. Lee, J. Phillips and M. Frenklach, Nano Lett., 2008, 8, 2012.

25 A. A. Balandin, S. Ghosh, W. Z. Bao, I. Calizo, D. Teweldebrhan, F. Miao and C. N. Lau, Nano Lett., 2008, 8, 902.

26 O. Akhavan, ACS Nano, 2010, 4, 4174.

27 A. Mukherji, B. Seger, G. Q. Lu and L. Z. Wang, ACS Nano, 2011, 5, 3483.

28 Y. H. Ng, A. Iwase, N. J. Bell, A. Kudo and R. Amal, Catal. Today, 2011, 164, 353.

29 K. Sayama, H. Hayashi, T. Arai, M. Yanagida, T. Gunji and H. Sugihara, Appl. Catal., B, 2010, 94, 150.

30 J. H. Li, W. L. Kang, X. Yang, X. D. Yu, L. L. Xu, Y. H. Guo, L. B. Fang and S. D. Zhang, Desalination, 2010, 255, 107.

31 R. Y. Zheng, Y. Guo, C. Jin, J. L. Xie, Y. X. Zhu and Y. C. Xie, J. Mol. Catal. A: Chem., 2010, 319, 46.

32 M. Hirata, T. Gotou, S. Horiuchi, M. Fujiwara and M. Ohba, Carbon, 2004, 42, 2929.

33 J. Guo, S. Zhu, Z. Chen, Y. Li, Z. Yu, Q. Liu, J. Li, C. Feng and D. Zhang, Ultrason. Sonochem., 2011, 18, 1082.

34 R. Bissessur, P. K. Y. Liu and S. F. Scully, Synth. Met., 2006, 156, 1023.

35 W. Thamjaree, W. Nhuapeng and T. Tunkasiri, Ferroelectrics Letters Section, 2004, 31, 79.

36 C. Wen, X. Li, D. Y. Sun, J. Q. Guan, X. X. Liu, Y. R. Lin, S. Y. Tang, G. Zhou, J. D. Lin and Z. H. Lin, Spectrosc Spect Anal, 2005, 25,54 .

37 D. Graf, F. Molitor, K. Ensslin, C. Stampfer, A. Jungen, C. Hierold and L. Wirtz, Nano Lett., 2007, 7, 238.

38 S. M. Zhu, X. Y. Liu, Z. X. Chen, C. J. Liu, C. L. Feng, J. J. Gu, Q. L. Liu and D. Zhang, J. Mater. Chem., 2010, 20, 9126.

39 M. Niederberger, G. Garnweitner, F. Krumeich, R. Nesper, H. Colfen and M. Antonietti, Chem. Mater., 2004, 16, 1202.

40 A. K. Manna and S. K. Pati, Chem.-Asian J., 2009, 4, 855.

41 R. Abe, T. Takata, H. Sugihara and K. Domen, Chem. Commun., $2005,3829$.

42 R. Amal, Y. H. Ng, A. Iwase, N. J. Bell and A. Kudo, Catal. Today, $2011, \mathbf{1 6 4}, 353$.

43 X. Xiao and W. D. Zhang, Prog Chem, 2011, 23, 657.

44 Y. Cong, F. Chen, J. L. Zhang and M. Anpo, Chem. Lett., 2006, 35, 800. 